\title{
Comparison of endocervical swabs to cultured isolates for the detection of antimicrobial resistance determinants in Neisseria gonorrhoeae
}

\author{
G Oree, ${ }^{1}$ (i) M Naicker, ${ }^{1}$ (D) HC Maise, ${ }^{2}$ (D) NS Abbai' \\ ${ }^{1}$ School of Clinical Medicine Research Laboratory, Nelson R Mandela School of Medicine, University of KwaZulu-Natal, South Africa \\ ${ }^{2}$ Department of Obstetrics and Gynaecology, School of Clinical Medicine, Nelson R Mandela School of Medicine, \\ University of KwaZulu-Natal, South Africa
}

Corresponding author, email: abbain@ukzn.ac.za

\begin{abstract}
Background: The global emergence of antimicrobial resistance (AMR) in Neisseria gonorrhoeae to various antibiotics is a public health concern. To date, there have been no published South African studies that have compared the primary swab to the cultured isolates for the detection of N. gonorrhoeae AMR determinants. This study provides data on such a comparison.

Methods: Paired endocervical swabs were collected from 307 pregnant women. The first swab was stored in an Amies charcoal transport media for culture assessment and the second swab was used for the molecular detection of resistant determinants. Specific targets (genes/plasmids/mutations) associated with resistance to penicillin, tetracycline, ciprofloxacin, spectinomycin, cefixime, azithromycin and ceftriaxone were detected from both the cultured isolates and the endocervical swabs.
\end{abstract}

Results: Of the 307 samples tested in this study, only six samples tested positive for culture. A total of 24 samples tested positive for N. gonorrhoeae with the quantitative polymerase chain reaction (qPCR) assay. The six samples which tested positive for culture fell within the qPCR positives group. Since this study was designed to directly compare the culture swabs to the endocervical swabs for the detection of AMR determinants, the current analysis included only the six culture samples and six paired endocervical swab samples $(n=6)$. All six isolates were resistant to tetracycline and penicillin $\mathrm{G}$ while five of the six isolates were resistant to ciprofloxacin. All isolates were susceptible to the remaining antimicrobials. There was a $100 \%$ correlation between the cultured isolates and endocervical swabs for detecting the specific AMR determinants, conferring resistance to tetracycline, penicillin G and ciprofloxacin.

Conclusion: Based on the findings of this study, tracking emerging patterns of resistance from the molecular level using only the endocervical swabs may serve as an attractive future research direction.

Keywords: Neisseria gonorrhoeae, penicillin, ciprofloxacin, tetracycline, spectinomycin, azithromycin, cefixime, ceftriaxone, antimicrobial resistance, pregnant women

\section{Introduction}

Neisseria gonorrhoeae ( $N$. gonorrhoeae) is the causative agent of gonorrhoeae and is reported to be among one of the most prevalent bacterial sexually transmitted infections (STIs) globally. ${ }^{1}$ $N$. gonorrhoeae has the remarkable ability to acquire antibiotic resistance through molecular mutations, creating a worldwide public health concern. ${ }^{2-4}$ This STI is included in the World Health Organization's (WHO) global priority list of antibiotic-resistant bacteria as it has developed resistance to every antimicrobial drug recommended for treatment since the introduction of the sulphonamides in the 1930s. ${ }^{5}$

A 2018 WHO global surveillance study revealed that 87 million new infections occurred in adolescents and adults between the ages of 15 to 49, in 2016, with sub-Saharan Africa displaying the highest incidence for $N$. gonorrhoeae. 6,7 South African studies have previously reported prevalence rates for $N$. gonorrhoeae of $3-11 \%$ in women. ${ }^{1,8,9} \mathrm{~A}$ study conducted in women attending antenatal care had recently reported a prevalence of $1.3 \%$ for $N$. gonorrhoeae. ${ }^{10}$ Untreated $N$. gonorrhoeae infections are associated with adverse outcomes such as reproductive health issues, obstetric morbidity, and the acquisition of Human Immunodeficiency Virus (HIV) and other STIs. ${ }^{1,7,11-19}$

N. gonorrhoeae has been reported to be asymptomatic, thereby allowing the survival of this microorganism to persist. ${ }^{20}$ The global emergence of drug resistance in $N$. gonorrhoeae to previous and current antibiotic treatments is a public health concern since this infection may become untreatable. ${ }^{21-23}$ This microorganism has phenotypic variability through the differential expression of existing parts of the microorganism's genome as well as genotypic variation through acquiring and incorporating new genetic material by conjugation or transformation..$^{20}$ Another important characteristic is the antigenic variability that $N$. gonorrhoeae acquires through obtaining genetic material from other organisms which contributes to its various mechanisms of resistance. ${ }^{24}$ This demonstrates that continuous surveillance of the emerging resistance or susceptibility patterns of this pathogen is critical. 
It has been previously reported that plasmid-mediated penicillinase-producing N. gonorrhoeae (PPNG) are $\beta$-lactamase producing and associated with three plasmid types that confer penicillin resistance (Asian, African and Toronto types). ${ }^{21,25,26}$ Tetracycline resistant $N$. gonorrhoeae (TRNG) is conferred by the tet $M$ gene which is harboured by two conjugative plasmids (American and Dutch). 21,25,26 Ciprofloxacin resistance has been frequently linked to the $g y r A$ and $\operatorname{parC}$ mutations, with predominance of the Ser-91 gyrA status.9,20,27 A transfer of the $r p s E$ gene allele encoding the mutant ribosomal protein S5 (RPS5) results in a substitution mutation of Thr- $24 \rightarrow$ Pro, subsequently disrupting the binding of spectinomycin to the ribosomal target and thereby promoting resistance. ${ }^{28}$ High-level azithromycin resistance has recently been observed in association with mutations in the mef efflux pump gene, and the $m$ trR regulatory and $m \operatorname{tr} C D E$ structural genes. ${ }^{29,30}$ Point mutations in the 235 rRNA region have previously been described to confer azithromycin resistance. ${ }^{31}$ Resistance towards third-generation cephalosporins such as cefixime and ceftriaxone has been observed in many countries, including South Africa. ${ }^{2} \mathrm{~A}$ recombination of gonococcal penA with penA genes of commensal Neisseria species produces a mosaic-like pen $A$ structure, associated with conferring this resistance. ${ }^{32,33}$ Alternatively, modifications in $m t r R$ and por $B$ are associated with decreased drug accumulation. ${ }^{34}$

Antimicrobial resistance (AMR) studies on N. gonorrhoeae have been based on minimum inhibition concentration (MIC) by using culture. However, maintaining the viability of $N$. gonorrhoeae is a challenge due to unsuccessful growth, poor transportation and storage. ${ }^{35}$ Detection of resistance targets and mutations without the need for culture serves as a much more attractive alternative for AMR studies. In this study, pregnant women had provided paired endocervical swabs for culture and molecular assessments. DNA was extracted from both the cultured samples and the primary endocervical swabs. The paired extracted DNA was used to detect gene targets and identify determinants associated with resistance to penicillin, tetracycline, ciprofloxacin, spectinomycin, azithromycin, cefixime and ceftriaxone by the real-time polymerase chain reaction (RT-PCR). The aim of this study was to compare the primary swab to the cultured isolates for the detection of $N$. gonorrhoeae AMR determinants. To date, there have been no published South African studies that have investigated the sensitivity of the primary endocervical swab against culture for the detection of AMR determinants in this pathogen.

\section{Materials and methods}

\section{Study setting and population}

The study population included 307 pregnant women $(n=307)$ from the antenatal clinic of the King Edward VIII Hospital (KEH) in Durban, KwaZulu-Natal. The study population was recruited between November 2018 and July 2019. Eligibility of participants was based on the following aspects: women who were 18 years and older; willingness to provide informed consent; willingness to provide data on sexual behaviour, demographics and clinical history by completing a structured questionnaire; and willingness to undergo a pelvic examination to provide two endocervical swab samples.

\section{Sample collection and processing}

Each participant underwent a pelvic examination conducted by a gynaecologist and paired endocervical swab samples were collected. The first swab was placed in an Amies charcoal transport media (LASEC, South Africa) immediately after collection. The second swab was placed in a dry sterile tube. Both swabs were stored at room temperature before being processed at the School of Clinical Medicine's Research Laboratory, UKZN. The swabs were processed within four hours of sample collection. The dry swab was immersed in $2 \mathrm{ml}$ of phosphate buffered saline $(\mathrm{pH} 7.4)$ and vortexed to dislodge the sample material from swab, after which the cervical fluid was stored at $-20^{\circ} \mathrm{C}$ until further molecular analysis. The vortexed swab was discarded. ${ }^{36}$

\section{Culture detection of $\mathbf{N}$. gonorrhoeae}

The swabs from the Amies charcoal transport medium were plated onto New York City Agar plates and incubated for 24 to 48 hours at $37^{\circ} \mathrm{C}$ in the presence of $5 \% \mathrm{CO}_{2} \cdot{ }^{36}$ Suspected colonies were sub-cultured onto Chocolate Agar plates and incubated for a further 24 hours in the presence of $5 \% \mathrm{CO}_{2}$ at $37^{\circ} \mathrm{C}$. To confirm the identity of the isolates, Gram staining, oxidase, catalase and superoxol tests were conducted. ${ }^{36}$

\section{Preparation of culture DNA for extraction}

Culture-confirmed clinical isolates were re-plated onto Chocolate Agar plates. A set of $\mathrm{WHO}$ reference strains were also plated from storage at $-80^{\circ} \mathrm{C}$. The culture plates were incubated for 24 hours at $37^{\circ} \mathrm{C}$ in the presence of $5 \% \mathrm{CO}_{2}$. Following growth on the Agar plate, an inoculum with $1 \mathrm{ml}$ Brain-Heart Infused Broth (LASEC, South Africa) was then prepared for both the clinical isolates and the $\mathrm{WHO}$ reference strains. These samples were incubated for 30 minutes at $37{ }^{\circ} \mathrm{C}$ in the presence of $5 \% \mathrm{CO}_{2}$.

\section{DNA extraction from cultured isolates}

The inoculum was then used for the isolation of genomic DNA using the Wizard Genomic DNA Purification Kit (Promega Corp., Madison, United States of America) according to the manufacturer's guide. A NanoDrop spectrophotometer (ThermoFisher Scientific, South Africa) was used to assess the concentration and purity of the extracted DNA. The extracted DNA was stored at $-20^{\circ} \mathrm{C}$ until further use.

\section{DNA isolation from the endocervical sample}

The stored cervical fluid samples were retrieved from the freezer, allowed to thoroughly thaw and then subjected to DNA extraction. The suspension was centrifuged at $14000 \mathrm{rpm}$ for $10 \mathrm{~min}$ and the supernatant was discarded. Recovered pellets were then subjected to a DNA extraction method using the PureLink Microbiome Kit (ThermoFisher Scientific, Waltham, Massachusetts, United States of America), according to the manufacturer's instructions. A NanoDrop spectrophotometer (ThermoFisher Scientific, South Africa) was used to assess the concentration and purity of the extracted DNA. 


\section{Detection of $\mathbf{N}$. gonorrhoeae from the endocervical sample}

The pre-designed commercially available TaqMan quantitative PCR (qPCR) assay, specifically for $N$. gonorrhoeae (Assay ID: Ba04646252_s; ThermoFisher Scientific, United States of America), was used for the detection of this pathogen. Briefly, each reaction comprised $2.5 \mu \mathrm{l}$ of Fast Start $4 \mathrm{x}$ probe master mix, 0.5 $\mu \mathrm{I}$ FAM-labelled probe/primer mix and $2 \mu \mathrm{l}$ sample DNA in a final volume of $5 \mu$ l. Amplification was performed on a QuantStudio ${ }^{\mathrm{TM}}$ 5 Real-Time PCR System with 1 cycle at $95{ }^{\circ} \mathrm{C}$ for 30 seconds followed by 45 cycles of denaturation ( $95^{\circ} \mathrm{C}$ for 30 seconds) and annealing (60 ${ }^{\circ} \mathrm{C}$ for 30 seconds). Amplified fluorescent products were detected at completion of the annealing period. The raw fluorescent data that was automatically generated by the QuantStudio ${ }^{\text {TM }} 5$ Real-Time PCR System software-included cycling threshold $\left(C_{T}\right)$ values.

\section{Detection of molecular markers/genes associated with antimicrobial resistance}

The sequences of the primers used for the detection of the individual genes are shown in Table I. A no template control was used as a negative control and the WHO reference strains were used as a positive control to confirm validity of the PCR results. Conventional PCR was performed for all gene targets in a final volume of $25 \mu \mathrm{l}$ and comprised 12.5 $\mu \mathrm{l}$ DreamTaq PCR Mastermix 2x (ThermoFisher Scientific, United States of America), $0.5 \mu \mathrm{l}$ of each $(10 \mu \mathrm{M})$ primer, $2 \mu \mathrm{l}$ template DNA and nuclease free water. PCR amplicons were separated on a $1 \%$ agarose gel by electrophoresis and visualised using a UV transilluminator (GeneGenius, Syngene, Maryland, United States of America).

\section{Detection of azithromycin resistance determinants}

The 23S rRNA gene was amplified in order to identify mutations that are responsible for conferring azithromycin resistance (see Table I). Amplification was performed at an initial denaturation of $95^{\circ} \mathrm{C}$ for 5 minutes, followed by 30 cycles of $95^{\circ} \mathrm{C}$ for 1 minute (denaturation), $60{ }^{\circ} \mathrm{C}$ for 1 minute (annealing) and $72{ }^{\circ} \mathrm{C}$ for 1 minute (extension). A final extension step at $72^{\circ} \mathrm{C}$ for 5 minutes was included.

\section{Detection of cefixime and ceftriaxone resistance determinants}

The pen $A$ and por genes were amplified to identify resistant determinants for cefixime and ceftriaxone. Primers PA1 and PA2 were used for the amplification of the penA gene (Table I). Amplification was performed with an initial denaturation of $95^{\circ} \mathrm{C}$ for 3 minutes, followed by 30 cycles of $95^{\circ} \mathrm{C}$ for 1 minute (denaturation), $48{ }^{\circ} \mathrm{C}$ for 1 minute (annealing) and $72{ }^{\circ} \mathrm{C}$ for 1 minute (extension) and a final extension step at $72{ }^{\circ} \mathrm{C}$ for 5 minutes.

The PorB1 and PorB2 primers were used for the amplification of the por gene (Table I). Amplification was performed at an initial denaturation of $95^{\circ} \mathrm{C}$ for 5 minutes, followed by 30 cycles of 95 ${ }^{\circ} \mathrm{C}$ for 1 minute (denaturation), $56^{\circ} \mathrm{C}$ for 1 minute (annealing) and $72{ }^{\circ} \mathrm{C}$ for 1 minute (extension). A final extension step at $72^{\circ} \mathrm{C}$ for 5 minutes was included.

\section{Detection of spectinomycin resistance determinants}

The $r p s E$ gene was amplified to identify spectinomycin resistant determinants (Table I). Cycling conditions included initial denaturation of $95^{\circ} \mathrm{C}$ for 1 minute, followed by 30 cycles of $95^{\circ} \mathrm{C}$ for 1 minute (denaturation), $48^{\circ} \mathrm{C}$ for 1 minute (annealing) and $72^{\circ} \mathrm{C}$

Table I: Primer sequences and targeted genes for the antibiotic resistant determinants investigated in this study

\begin{tabular}{|c|c|c|c|c|}
\hline Antibiotic & Primer name & Primer sequence $\left(5^{\prime}-3^{\prime}\right)$ & Targeted gene & $\begin{array}{c}\text { Reference } \\
\text { sequence/positive control }\end{array}$ \\
\hline \multirow{2}{*}{ Azithromycin } & $23 S$ & GCGACCATACCAAACACCCACAGG & \multirow{2}{*}{$\begin{array}{l}\text { Point mutations in } 235 \text { rRNA } \\
\text { regions in allele } 2(37)\end{array}$} & \multirow{2}{*}{ WHO-Y } \\
\hline & rRNAR-allele 2 & & & \\
\hline $\begin{array}{l}\text { Cefixime and } \\
\text { Ceftriaxone }\end{array}$ & PA2 & ACAATCTCGTTGATACTCG & penA gene (38) & WHO-Y \\
\hline \multirow{2}{*}{$\begin{array}{l}\text { Cefixime and } \\
\text { Ceftriaxone }\end{array}$} & PorB1 & AAAGGCCAAGAAGACCTCGGC & \multirow[t]{2}{*}{ por gene (38) } & \multirow[t]{2}{*}{ WHO-Y } \\
\hline & PorB2 & GAGAAGTCGTATTCCGCACCG & & \\
\hline \multirow[t]{2}{*}{ Spectinomycin } & $5 S-F$ & TGGCAAAACATGA AATTGAAG & \multirow[t]{2}{*}{ rpsE gene (39) } & \multirow{2}{*}{$\begin{array}{l}\text { NG } 3.1 \text { 30S ribosomal } \\
\text { protein S5 (Genbank } \\
\text { accession: KF021592) }\end{array}$} \\
\hline & $5 S-R$ & GCCATGGTTAACTCCCAAAA & & \\
\hline \multirow[t]{4}{*}{ Penicillin G } & GC1F & AACTCACGGACAAAATCACGG & \multirow{4}{*}{$\begin{array}{l}\beta \text {-lactamase producing } \\
\text { plasmid ( } 25)\end{array}$} & \multirow[t]{4}{*}{-} \\
\hline & GC2F & CACCTATAAATCTCGCAAGCC & & \\
\hline & GC3R & AACGCAAGCAGGACGAAATC & & \\
\hline & GC4R & ССТCСАССTTCATCCTCAGC & & \\
\hline \multirow[t]{2}{*}{ Tetracycline } & TetMF & ACTGTTGAACCGAGYAAACCT & \multirow[t]{2}{*}{ TetM gene (25) } & \multirow[t]{2}{*}{-} \\
\hline & TetMR & TCTATCCGACTATTTGGACGACG & & \\
\hline \multirow[t]{2}{*}{ Ciprofloxacin } & GyrAF & CGGCGCGTACTGTACGCGATGCA & \multirow[t]{2}{*}{ Gyrase A gene (26) } & \multirow[t]{2}{*}{ WHO-Y } \\
\hline & GyrAR & ATGTCTGCCAGCATTTCATGTGAGA & & \\
\hline
\end{tabular}


for 1 minute (extension) and a final extension step at $72^{\circ} \mathrm{C}$ for 5 minutes.

\section{Detection of penicillin resistance determinants}

A multiplex PCR was used to detect $\beta$-lactamase-producing plasmid types using $0.25 \mathrm{ul}(10 \mu \mathrm{M})$ of each primer, with protocols previously described by Luwang ${ }^{25}$ and Tanaka ${ }^{26}$. The reaction mixture consisted of $5 \mu$ of template DNA together with all the reagents previously mentioned. The PCR cycling conditions included an initial denaturation at $94{ }^{\circ} \mathrm{C}$ for 5 minutes, followed by 35 cycles each consisting of denaturation at $94{ }^{\circ} \mathrm{C}$ for 30 seconds, annealing at $58^{\circ} \mathrm{C}$ for 1 minute, extension at $72{ }^{\circ} \mathrm{C}$ for 1 minute and 30 seconds and a final extension at $72{ }^{\circ} \mathrm{C}$ for 10 minutes.

\section{Detection of tetracycline resistance determinants}

Tetracycline resistance plasmid types were detected by PCR using the primers as shown in Table I. The PCR cycling conditions included an initial denaturation at $94{ }^{\circ} \mathrm{C}$ for 5 minutes, followed by 35 cycles each consisting of denaturation at $94{ }^{\circ} \mathrm{C}$ for 30 seconds, annealing at $56^{\circ} \mathrm{C}$ for 1 minute, extension at $72{ }^{\circ} \mathrm{C}$ for 1 minute and 30 seconds and a final extension at $72{ }^{\circ} \mathrm{C}$ for 10 minutes. Detection of the specific plasmid type was performed by digestion of the PCR amplicon with Hinfl (New England Biolabs, United States of America). The digests were incubated at $37^{\circ} \mathrm{C}$ for 1 hour followed by heat inactivation at $80^{\circ} \mathrm{C}$ for 20 minutes and visualised on a $1.5 \%$ agarose gel.

\section{Detection of ciprofloxacin resistance determinants}

The GyraAF and GyrAR primers were used for the amplification reactions. Cycling conditions included an initial denaturation at $94{ }^{\circ} \mathrm{C}$ for 5 minutes, followed by 35 cycles each consisting of denaturation at $94{ }^{\circ} \mathrm{C}$ for 30 seconds, annealing at $60{ }^{\circ} \mathrm{C}$ for 1 minute, extension at $72{ }^{\circ} \mathrm{C}$ for 1 minute and 30 seconds and a final extension at $72{ }^{\circ} \mathrm{C}$ for 10 minutes. Detection of the Ser- 91 mutation which confers ciprofloxacin resistance was performed by digestion of the PCR amplicon with Hinfl (New England Biolabs, United States of America). The digests were incubated at $37{ }^{\circ} \mathrm{C}$ for 1 hour followed by heat inactivation at $80^{\circ} \mathrm{C}$ for 20 minutes and visualised on a $1.5 \%$ agarose gel.

\section{Sequencing of PCR amplicons to confirm identify and alignment}

To confirm the identity of the PCR amplicons and identify mutations responsible for conferring resistance, Sanger sequencing was performed. The samples were sequenced at Inqaba Biotechnological Industries in Pretoria, South Africa. Sequencing was performed on an ABI3500XL genetic analyser and the raw sequence data was edited using Chromas software V2.6.5 (Technelysium, Queensland, Australia). The identity of the edited sequences was confirmed using the National Center for Biotechnology Information (NCBI) Basic Local Alignment Search Tool (BLAST). Nucleotide sequences were translated using the ExPASy translate tool (https://web.expasy.org/translate/). In order to identify resistance conferring mutations, a multiple sequence alignment was performed using ClustalW (https:// www.genome.jp/tools-bin/clustalw). The alignment included
WHO reference strains which are resistant to the named antibiotics (carrying the mutations) and the paired culture and endocervical swab samples.

\section{Results}

\section{Detection of N. gonorrhoeae by culture and PCR}

Of the 307 samples tested in this study, only six samples tested positive for culture. A total of 24 samples tested positive for $N$. gonorrhoeae with the qPCR assay. The six samples which were positive for culture also fell within the GPCR positives group. Since this study was designed to directly compare the culture swabs to the endocervical swabs for the detection of AMR determinants, the current analysis included only the six culture samples and six paired endocervical swab samples $(n=6)$. The phenotypic resistance profiles for the six culture positive isolates were conducted previously (Supplementary Figure 1). The phenotypic results from the previous study showed that all isolates were penicillin resistant $(12-64 \mathrm{mg} / \mathrm{L})$. The isolates also were observed to have intermediate $(1 \mathrm{mg} / \mathrm{L})$ and resistant (1.9-32 $\mathrm{mg} / \mathrm{L})$ profiles to tetracycline and ciprofloxacin resistance was observed for five of the six isolates $(1.16-3 \mathrm{mg} / \mathrm{L})$. All isolates were susceptible to spectinomycin, azithromycin, cefixime and ceftriaxone.

\section{Identification of mutations associated with azithromycin resistance}

The 235 rRNA was amplified in all cultured samples and five of the six endocervical swab samples. The PCR amplicons were confirmed to be the $N$. gonorrhoeae strain 32380235 ribosomal RNA gene, complete sequence (Genbank number: KT954110.1). Figure 1 represents the sequence alignment for the WHO reference strain and selected paired culture and endocervical samples. The mutations that are responsible for conferring resistance to azithromycin were absent in the clinical samples analysed; however, these were present in the WHO reference strain. The $\mathrm{WHO}$ reference strain exhibited a $\mathrm{C} \rightarrow \mathrm{T}$ nucleotide substitution which has been associated with azithromycin re-

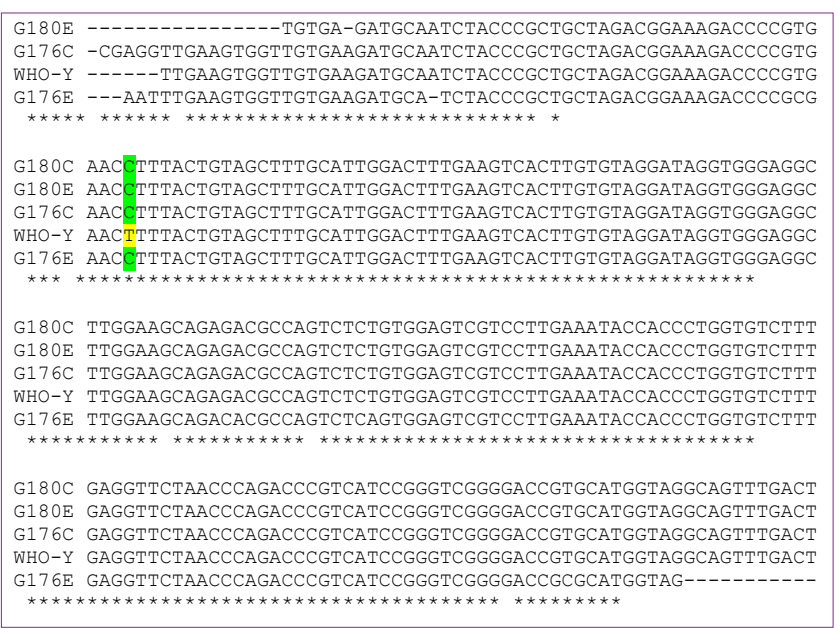

Figure 1: ClustalW multiple sequence alignment for the identification of point mutations in $235 \mathrm{rRNA}$ regions in alleles 2 for azithromycin resistance

C - culture DNA, E - endocervical DNA, WHO-Y - positive control The presence of the mutation $(C \rightarrow T)$ is shown as highlighted text 
sistance (Figure 1). This was in line with the observed phenotypic resistance profile previously conducted on these isolates, in which none of the clinical isolates were azithromycin resistant; however, the WHO reference strain was resistant.

\section{Identification of mutations associated with cefixime/ ceftriaxone resistance}

The por and penA genes were amplified in all cultured samples and five of the six endocervical swab samples. For the penA amplicons, the sequencing results confirmed its identity to be Penicillin-binding protein 2, partial [Neisseria gonorrhoeae] GenBank number: AFJ54623.1. Similarly for por, the amplicons were confirmed to be porin [Neisseria gonorrhoeae] Genbank number:WP_057321029.1.

According to Figure 2, mutations in the por gene responsible for resistance to cefixime and ceftriaxone was absent in the clinical samples. However, the WHO reference strain was observed to have deletions of tyrosine, lysine and histidine amino acids and substitutions of the following amino acids: Gln $\rightarrow$ Tyr, Val $\rightarrow$ Ala, Ala $\rightarrow$ Gly, Ala $\rightarrow$ Val and Asn $\rightarrow$ Gln (Figure 2). This also links

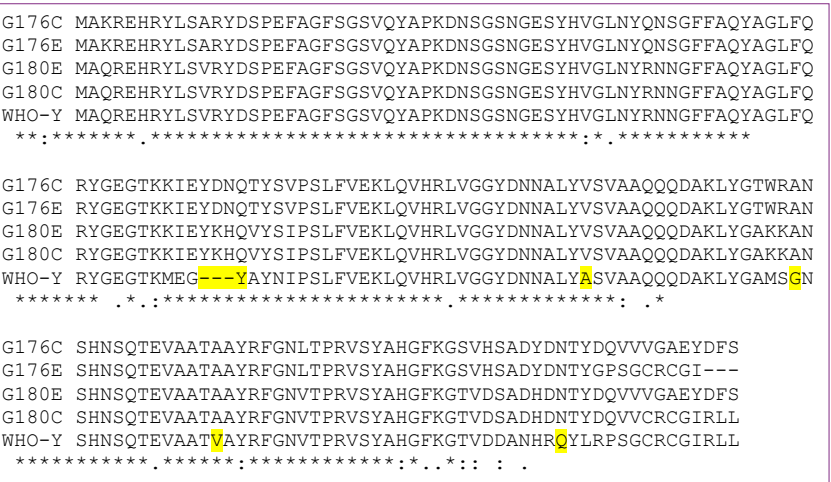

Figure 2: ClustalW multiple sequence alignment for identification of mutations in por gene for cefixime/ceftriaxone resistance $C$ - culture DNA, E - endocervical DNA, WHO-Y - positive control The presence of the mutations are shown as highlighted text

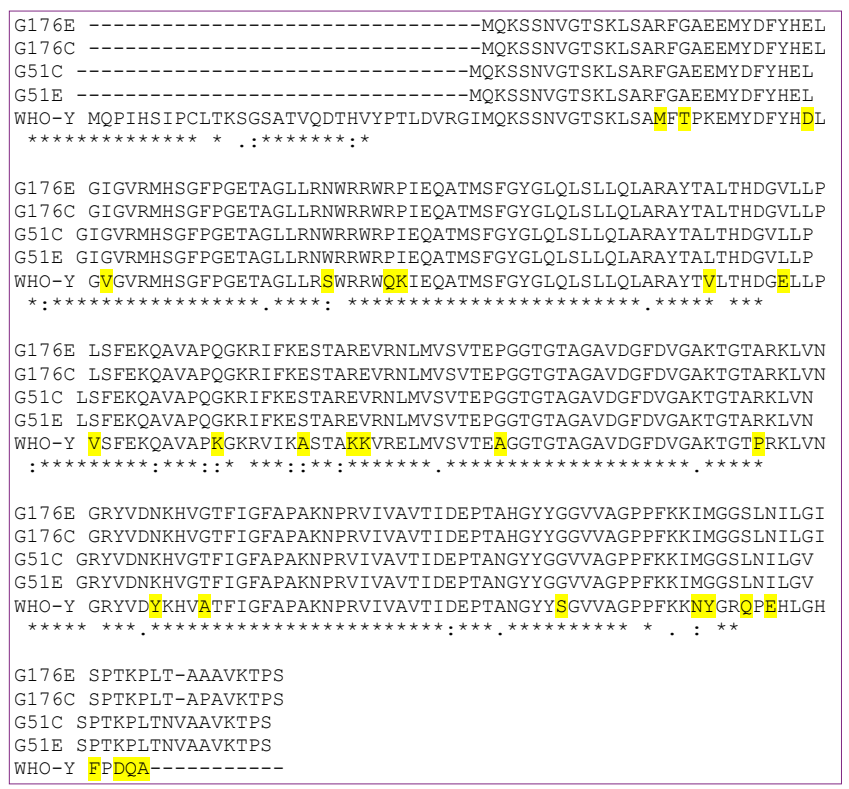

Figure 3: ClustalW multiple sequence alignment for identification of mutations in penA gene for cefixime/ceftriaxone resistance

$C$ - culture DNA, E - endocervical DNA, WHO-Y - positive control

The presence of the mutations are shown as highlighted text to the previous phenotypic resistance profile of the isolates in which none of the six culture positives showed resistance to either antibiotic.

Similarly, sequences obtained from the PCR for the penA gene showed multiple substitution mutations (Arg $\rightarrow$ Met, Gly $\rightarrow$ Thr, $\mathrm{Glu} \rightarrow \mathrm{Asp}$, Ile $\rightarrow$ Val, Asn $\rightarrow$ Ser, Arg $\rightarrow$ Gln, Pro $\rightarrow$ Lys, Ala $\rightarrow$ Val, Val $\rightarrow$ Glu, Leu $\rightarrow$ Val, Gln $\rightarrow$ Lys, Glu $\rightarrow$ Ala, Arg $\rightarrow$ Lys, Glu $\rightarrow$ Lys, Pro $\rightarrow$ Ala, Ala $\rightarrow$ Pro, Asn $\rightarrow$ Tyr, Gly $\rightarrow$ Ala, Gky $\rightarrow$ Ser, Ile $\rightarrow$ Asn, Met $\rightarrow$ Tyr, Ser $\rightarrow$ Gln, Asn $\rightarrow$ Glu, Ser $\rightarrow$ Phe, Thr $\rightarrow$ Asp, Lys $\rightarrow \mathrm{Gln}$, Pro $\rightarrow$ Ala) in the WHO reference strain, which were not present in the clinical samples (Figure 3).

\section{Identification of mutations associated with spectinomycin resistance}

The rpsE gene, which carries mutations associated with spectinomycin resistance, was amplified in all the culture samples and five of the six endocervical swab samples. The amplicons were confirmed to be $N$. gonorrhoeae strain 3mut SPC 30S subunit ribosomal protein S5 (rpsE) gene, Genbank number: GU395615.1. For this antibiotic, there was no available WHO reference strain which was resistant to spectinomycin, therefore the alignment was conducted using the $r p s E$ sequence of the N. gonorrhoeae strain NG 3.1 30S ribosomal protein S5 (Genbank accession: KF021592) which carries the mutation for spectinomycin resistance. ${ }^{28}$ A substitution mutation (Thr-24 $\rightarrow$ Pro) was observed in the KF021592 strain with no mutation observed in either the culture or the endocervical sequences (Figure 4). This is in keeping with the AMR data on these isolates as resistance to spectinomycin was not observed.

\section{Identification of penicillin, tetracycline and ciprofloxacin resistance determinants}

The $\beta$-lactamase producing plasmid, tet $M$ gene and gyrase $A$ gene was shown to be present in all the clinical samples tested. The correlation of the PCR assays for the individual genes between the swabs compared to the cultured isolates was $100 \%$. The sensitivity of the PCR assays with both sample types was determined using the following formula: 40 [number of true positives/(number of true positives+number of false negatives)] $\mathrm{x} 100$

The tet $M$ gene was shown to be carried on the American typetet $M$ conjugative plasmid (Genbank number: GU479464.1). The

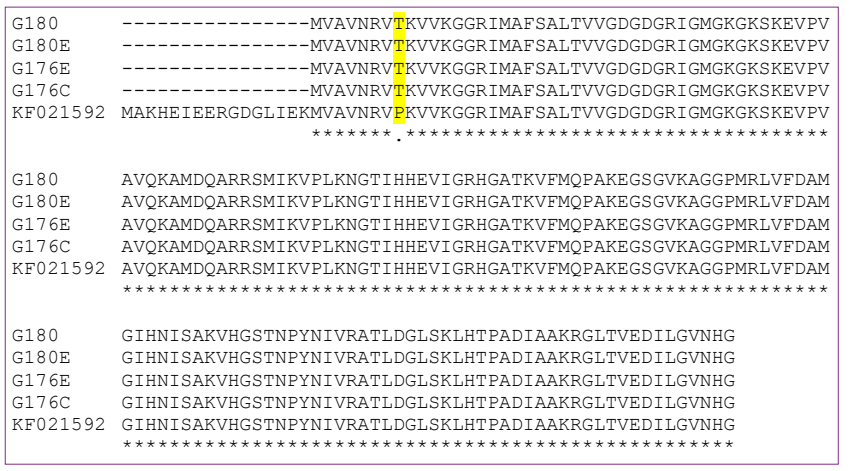

Figure 4: ClustalW multiple sequence alignment for identification of mutations in $r p s E$ gene for spectinomycin resistance

C - culture DNA, E - endocervical DNA, Genbank reference sequence (KF021592) The presence of the mutation is shown as highlighted text 
multiplex PCR for the $\beta$-lactamase-producing plasmid carried the N. gonorrhoeae strain African-TEM 1-MIC16 plasmid PJD5, complete sequence (Genbank Number: MK973084.1). The PCR amplicons corresponding to the gyraseA gene was confirmed to be the gyraseA gene from $N$. gonorrhoeae, DNA gyrase subunit A, partial [N. gonorrhoeae] (Genbank number: APU93729.1). The Ser-91 mutation which was detected by digestion of the gyraseA PCR amplicon with Hinfl was shown to be present in both the culture and the endocervical swab samples of five of the six sample pairs. The presence of the digestion pattern matched the AMR results since there was one isolate which was susceptible to ciprofloxacin and, hence, did not carry the mutation.

\section{Discussion}

N. gonorrhoeae is one of the most prevalent STIs globally and has acquired AMR to various antibiotics used in its treatment over the years. Data on plasmid types and antibiotic resistant genes illustrates that this pathogen harbours are fundamental for monitoring the emergence and spread of antibiotic resistance. ${ }^{41,42}$ The majority of studies conducted in previous years have focused on the detection of AMR to antibiotics using culture-based techniques. ${ }^{43-45}$ In this study, a total of six isolates of $N$. gonorrhoeae were detected by culture-based assays. However, 24 samples tested positive for this pathogen when detected from the endocervical swabs using qPCR. Based on the low recovery rate of isolates with culture, this study investigated the performance of the endocervical swabs against the cultured isolates for the detection of AMR patterns. Specific genes that carry mutations associated with resistance to azithromycin, cefixime, ceftriaxone, spectinomycin and ciprofloxacin were investigated. The presence of plasmids that carry the resistance determinants for penicillin $G$ and tetracycline were also investigated.

Specific mutations associated with the 235 rRNA are responsible for low- and high-level resistance mutations to azithromycin and erythromycin. ${ }^{12,37,46,47}$ In this study, a C $\rightarrow$ T nucleotide substitution was observed only for the WHO azithromycin resistant strain. However, it was absent in the paired culture and swab samples. This finding correlates well with the AMR profile for these isolates which showed a lack of resistance to azithromycin (Supplementary Figure 1). There was a good correlation (83\%) between the cultured isolates and endocervical swabs for detecting the $23 S$ rRNA for further mutation scanning.

Specific mutations in the penA and por gene have been associated with resistance to cefixime and ceftriaxone. ${ }^{7}$ There was a good correlation (83\%) between the cultured isolates and endocervical swabs for detecting the por gene. However, mutations associated with cefixime and ceftriaxone resistance was absent in the study samples. The mutations (Gln $\rightarrow$ Tyr, Val $\rightarrow \mathrm{Ala}, \mathrm{Ala} \rightarrow \mathrm{Gly}$, Ala $\rightarrow$ Val and Asn $\rightarrow \mathrm{Gln}$ ) were detected in the WHO reference strain indicating the high sensitivity of the PCR and DNA sequencing assays for detecting the desired mutations from the endocervical swab samples. Similarly, another study reported on the following amino acid substitutions: Gly-101 $\rightarrow$ Lys, Ala-102 $\rightarrow$ Asp, Gly-101 $\rightarrow$ Lys, Ala-102 $\rightarrow$ Asn, Gly-101 $\rightarrow$ Asn and Ala-102 $\rightarrow$ Asp. $^{38,48}$ These mutations are often associated with a decrease in permeability to penicillin, cephalosporins and ciprofloxacin. ${ }^{49,50}$ The mutation scan was also $100 \%$ correlated with the AMR results for the isolates since none of the isolates were resistant to cefixime or ceftriaxone.

A previous study that investigated mutations in the penA mosaic allele (PBP 2) which showed reduced susceptibility to cefixime and ceftriaxone in $N$. gonorrhoeae revealed that a substitution of Ala-501 $\rightarrow$ Val was the cause of this reduced susceptibility. ${ }^{48,51}$ Upon further investigation, that study revealed that the PBP 2 pattern XVII contained an Ala-501 $\rightarrow$ Val substitution which was confirmed by a modelling study to cause a conformational alteration of the $\beta$-lactam binding pocket leading to a reduction in susceptibility to cephems. ${ }^{51}$ Our findings are similar to other studies since the Ala $\rightarrow$ Val substitution was detected in the WHO reference strain. ${ }^{51}$ No mutations were observed with paired culture and endocervical samples despite yielding successful PCR and DNA sequencing results. The lack of resistance conferring mutations correlates well with the AMR patterns for the isolates since susceptibility to cefixime and ceftriaxone was observed in these isolates (Supplementary Figure 1).

Resistance to spectinomycin is associated with mutations in the rpsE gene. ${ }^{28}$ This study used the $N$. gonorrhoeae strain NG 3.1 30 S ribosomal protein S5 (Genbank accession: KF021592) as the positive control to determine spectinomycin resistance. A study conducted by llina et al. ${ }^{28}$ illustrated that the spectinomycin resistant strain (N. gonorrhoeae strain NG $3.130 \mathrm{~S}$ ribosomal protein S5 [Genbank accession: KF021592]) carried a substitution mutation of Thr- $24 \rightarrow$ Pro. The culture and endocervical swab samples investigated in this study lacked these mutations indicating spectinomycin susceptibility. There was a good correlation between the PCR and sequencing assays for both sample types.

Ciprofloxacin resistance has been frequently associated with the gyrase $A$ and parC mutations, with predominance of the Ser91 gyraseA mutation. ${ }^{9,20,27}$ The presence of the Ser-91 mutation (identified by restriction digestion analysis) was present in both the cultured and endocervical samples. PCR detection and restriction analysis of the gyraseA gene can be used as a future method to track ciprofloxacin resistance from primary endocervical swabs especially in countries where ciprofloxacin is still used for the treatment of gonorrhoea.

A recent study conducted in South Africa by Rambaran et al. ${ }^{44}$ showed tetracycline resistance to be associated with the presence of the tet $M$ gene carried on a plasmid. The paired cultured and endocervical swab samples contained the American plasmid variant of the tet $M$ gene (identified by restriction digestion analysis). This is in keeping with recent findings from 2019 which showed that $90 \%$ of an investigated population contained the American plasmid variant, supporting the premise that the American plasmid variant of the tet $M$ gene originated on the African continent. ${ }^{44,53-55}$ Our findings confirm that surveillance for tetracycline resistance can be investigated 
from primary endocervical swabs since the molecular assays are in concordance with the AMR results for this antibiotic.

$N$. gonorrhoeae strains with plasmid-mediated resistance to penicillin contain plasmids with a bla $a_{\mathrm{TEM}-1}$ gene, encoding a TEM1-type $\beta$-lactamase. ${ }^{7}$ This enzyme hydrolyses the amide bond of penicillin and renders the penicillin inactive. ${ }^{7}$ The multiplex PCR employed in this study was successful in detecting the African type $\beta$-lactamase plasmid in both cultured and endocervical swab samples. The presence of the African type plasmid is in accordance with previous findings from South Africa. ${ }^{43}$ The PCR results are also in concordance with the AMR results for this antibiotic.

\section{Conclusion}

This comparative study for cultured and endocervical swab samples demonstrated the ability of endocervical samples to, in future, track emerging patterns of antimicrobial resistance in $N$. gonorrhoeae since it correlated well with the cultured samples. This approach minimises the need to culture isolates which require more stringent measure for sample collection, transportation, processing and maintaining viability of the gonococcus. Since the results of the molecular assays correlated well with AMR phenotypic results, tracking emerging patterns of resistance from the molecular level using only the endocervical swabs may serve as an attractive future research direction. This study was limited by the small sample size (six isolates). Therefore, it is recommended that future studies should attempt to obtain more isolates. Future studies on the molecular determinants for AMR should also consider investigating samples collected from different infection sites and not be subjected to endocervical samples only. Despite this limitation, our study was successful in tracking resistance using molecular determinants from the six paired samples.

\section{Acknowledgements}

The authors would like to thank all the women who participated in this study; the King Edward VIII Hospital Antenatal Clinic; and Prof. Magnus Unemo from the WHO Collaborating Centre for Gonorrhoeae and other STIs for the WHO reference strains.

\section{Conflict of interest}

The authors declare no potential conflicts of interest with respect to the research, authorship and/or publication of this article.

\section{Funding source}

This work was supported by the College of Health Science, University of KwaZulu-Natal (grant number: 640603) and the National Research Foundation (grant number: 112555).

\section{Ethical approval}

Full ethics approval for this study was granted by the Biomedical Research Ethics Committee (BREC) of the University of KwaZuluNatal (UKZN) (BE355/18).

\section{ORCID}

G Oree (ID https://orcid.org/0000-0003-4557-5185

M Naicker (D) https://orcid.org/0000-0002-6359-9511

HC Maise (iD https://orcid.org/0000-0003-0929-507

NS Abbai (i) https://orcid.org/0000-0003-2392-0574

\section{References}

1. Ramjee G, Abbai NS, Naidoo S. Women and sexually transmitted infections in Africa. Open J Obstet Gynecol. 2015;5(7):385-99. https://doi.org/10.4236/ ojog.2015.57056.

2. Lewis DA, Sriruttan C, Muller EE, et al. Phenotypic and genetic characterization of the first two cases of extended-spectrum-cephalosporin-resistant Neisseria gonorrhoeae infection in South Africa and association with cefixime treatment failure. J Antimicrob Chemother. 2013;68(6):1267-70. https://doi.org/10.1093/ $\mathrm{jac} / \mathrm{dkt034}$.

3. Unemo M, Golparian D, Sanchez-Buso L, et al. The novel 2016 WHO Neisseria gonorrhoeae reference strains for global quality assurance of laboratory investigations: phenotypic, genetic and reference genome characterization J Antimicrob Chemother. 2016;71(11):3096-108. https://doi.org/10.1093/jac/ dkw288.

4. Lahra MM. Surveillance of antibiotic resistance in Neisseria gonorrhoeae in the WHO Western Pacific and South East Asian Regions, 2010. Commun Dis Intell Q Rep. 2012;36(1):95-100.

5. Tacconelli E, Magrini N, Kahlmeter G. Global priority list of antibiotic-resistant bacteria to guide research, discovery, and development of new antibiotics. Geneva: World Health Organization; 2017.

6. World Health Organization. Report on global sexually transmitted infection surveillance 2018 [Internet]. Geneva: World Health Organization; 2018. Available from: https://www.who.int/reproductivehealth/publications/ stis-surveillance-2018/en/. Accessed 15 Jan 2019.

7. Unemo M, Shafer WM. Antimicrobial resistance in Neisseria gonorrhoeae in the 21st Century: past, evolution, and future. Clin Microbiol Rev. 2014;27(3):587-613. https://doi.org/10.1128/CMR.00010-14.

8. Abbai NS, Wand $H$, Ramjee $G$. Sexually transmitted infections in women participating in a biomedical intervention trial in Durban: prevalence, coinfections, and risk factors. J Sex Transm Dis. 2013;2013:358402. https://doi. org/10.1155/2013/358402.

9. Mlisana $K$, Naicker N, Werner $L$, et al. Symptomatic vaginal discharge is a poor predictor of sexually transmitted infections and genital tract inflammation in high-risk women in South Africa. J Infect Dis. 2012;206(1):6-14. https://doi. org/10.1093/infdis/jis298.

10. Pourabbas B, Rezaei Z, Mardaneh J, Shahian M, Alborzi A. Prevalence of Chlamydia trachomatis and Neisseria gonorrhoeae infections among pregnant women and eye colonization of their neonates at birth time, Shiraz, Southern Iran. BMC Infect Dis. 2018;18(1):1-4. https://doi.org/10.1186/s12879-018-3382-4.

11. Su WH, Tsou TS, Chen CS, et al. Are we satisfied with the tools for the diagnosis of gonococcal infection in females? J Chinese Med Assoc. 2011;74(10):430-4. https://doi.org/10.1016/j.jcma.2011.08.012.

12. Unemo M, Golparian D, Skogen V, et al. Neisseria gonorrhoeae strain with high-level resistance to spectinomycin due to a novel resistance mechanism (mutated ribosomal protein S5) Verified in Norway. Antimicrob Agents Chemother. 2013;57(2):1057-61. https://doi.org/10.1128/AAC.01775-12.

13. Bignell C, Unemo M. 2012 European guideline on the diagnosis and treatment of gonorrhoea in adults. Int J STD AIDS. 2013;24(2):85-92. https://doi. org/10.1177/0956462412472837.

14. World Health Organization. Global Action Plan to control the spread and impact of antimicrobial resistance in Neisseria gonorrhoeae. Geneva: World Health Organization; 2012.

15. Kidd S, Kirkcaldy RD, Burstein GR. Antimicrobial resistance in Neisseria gonorrhoeae. Adolesc Med State Art Rev. 2014;25(2):316-31.

16. Adachi K, Nielsen-Saines K, Klausner JD. Chlamydia trachomatis infection in pregnancy: the global challenge of preventing adverse pregnancy and infant outcomes in sub-Saharan Africa and Asia. Biomed Res Int. 2016;2016:9315757. https://doi.org/10.1155/2016/9315757.

17. Johnston VJ, Mabey DC. Global epidemiology and control of Trichomonas vaginalis. Curr Opin Infect Dis. 2008;21(1):56-64. https://doi.org/10.1097/ QCO.0b013e3282f3d999.

18. Newman L, Rowley J, Hoorn S, et al. Global estimates of the prevalence and incidence of four curable sexually transmitted infections in 2012 based on systematic review and global reporting. PLoS One. 2015;10(12):1-17. https://doi. org/10.1371/journal.pone.0143304.

19. Romoren M, Hussein F, Steen TW, et al. Costs and health consequences of chlamydia management strategies among pregnant women in sub-Saharan Africa. Sex Transm Infect. 2007;83(7):558-66. https://doi.org/10.1136/ sti.2007.026930. 
20. Patel AL, Chaudhry U, Sachdev D, et al. An insight into the drug resistance profile $\&$ mechanism of drug resistance in Neisseria gonorrhoeae. Indian J Med Res. 2011;134(10):419-31.

21. Fayemiwo SA, Muller EE, Gumede L, Lewis DA. Plasmid-mediated penicillin and tetracycline resistance among Neisseria gonorrhoeae isolates in South Africa: prevalence, detection and typing using a novel molecular assay. Sex Transm Dis. 2011;38(4):329-33. https://doi.org/10.1097/OLQ.0b013e3181fc695a.

22. Karim S, Bouchikhi C, Banani A, et al. Molecular antimicrobial resistance of Neisseria gonorrhoeae in a Moroccan Area. Infect Dis Obstet Gynecol. 2018;2018:7263849. https://doi.org/10.1155/2018/7263849.

23. Moodley P. Evolution in the trends of antimicrobial resistance in Neisseria gonorrhoeae isolated in Durban over a 5 year period: impact of the introduction of syndromic management. J Antimicrob Chemother. 2001;48(6):853-9. https:// doi.org/10.1093/jac/48.6.853.

24. Sarafian SK, Knapp JS. Molecular epidemiology of gonorrhea. Clin Microbiol Rev. 1989;2:S49-S55. https://doi.org/10.1128/CMR.2.Suppl.S49.

25. Lawung $R$, Cherdtrakulkiat $R$, Charoenwatanachokchai $A$, et al. One-step $P C R$ for the identification of multiple antimicrobial resistance in Neisseria gonorrhoeae. J Microbiol Methods. 2009;77(3):323-5. https://doi.org/10.1016/j. mimet.2009.03.009.

26. Tanaka M, Nakayama $H$, Haraoka $M$, et al. Antimicrobial resistance of Neisseria gonorrhoeae and high prevalence of ciprofloxacin-resistant isolates in Japan, 1993 to 1998. J Clin Microbiol. 2000;38(2):521-5. https://doi.org/10.1128/ JCM.38.2.521-525.2000

27. Deguchi T, Yasuda M, Nakano M, et al. Rapid screening of point mutations of the Neisseria gonorrhoeae parC gene associated with resistance to quinolones. J Clin Microbiol. 1997;35(4):948-50. https://doi.org/10.1128/JCM.35.4.948-950.1997.

28. Ilina EN, Malakhova MV, Bodoev IN, et al. Mutation in ribosomal protein S5 leads to spectinomycin resistance in Neisseria gonorrhoeae. Front Microbiol. 2013;4(JUL). https://doi.org/10.3389/fmicb.2013.00186.

29. Lucas CE, Balthazar JT, Hagman KE, Shafer WM. The MtrR repressor binds the DNA sequence between the $\mathrm{mtrR}$ and $\mathrm{mtrC}$ genes of Neisseria gonorrhoeae. J Bacteriol. 1997;179(13):4123-8. https://doi.org/10.1128/ JB.179.13.4123-4128.1997.

30. Luna VA, Cousin SJ, Whittington WLH, Roberts MC. Identification of the conjugative mefGene in clinical Acinetobacter junii and Neisseria gonorrhoeae isolates. Antimicrob Agents Chemother. 2000;44(9):2503-6. https://doi. org/10.1128/AAC.44.9.2503-2506.2000.

31. Demczuk W, Martin I, Peterson S, et al. Genomic epidemiology and molecular resistance mechanisms of azithromycin-resistant Neisseria gonorrhoeae in Canada from 1997 to 2014. J Clin Microbiol. 2016;54(5):1304-13. https://doi. org/10.1128/JCM.03195-15.

32. Ohnishi M, Golparian D, Shimuta K, et al. Is Neisseria gonorrhoeae initiating a future era of untreatable gonorrhea? Detailed characterization of the first strain with high-level resistance to ceftriaxone. Antimicrob Agents Chemother.2011;55(7):3538-45. https://doi.org/10.1128/AAC.00325-11.

33. Ameyama $S$, Onodera $S$, Takahata $M$, et al. Mosaic-like structure of penicillinbinding protein 2 gene (penA) in clinical isolates of Neisseria gonorrhoeae with reduced susceptibility to cefixime. Antimicrob Agents Chemother. 2002;46(12):3744-9. https://doi.org/10.1128/AAC.46.12.3744-3749.2002.

34. Hu M, Nandi S, Davies C, Nicholas RA. High-level chromosomally mediated tetracycline resistance in Neisseria gonorrhoeae results from a point mutation in the $r p s J$ gene encoding ribosomal protein $\mathrm{S} 10$ in combination with the $m t r R$ and penB resistance determinants. Antimicrob Agents Chemother. 2005;49(10):432734. https://doi.org/10.1128/AAC.49.10.4327-4334.2005.

35. Hassanzadeh P, Mardaneh J, Motamedifar M. Conventional agar-based culture method and nucleic acid amplification test (NAAT) of the cppB gene for detection of Neisseria gonorrhoeae in pregnant women endocervical swab specimens. Iran Red Crescent Med J. 2013;15(3):207-11. https://doi. org/10.5812\%2Fircmj.3726.

36. Perilla MJ, Ajello G, Bopp C, Elliot J, Facklam R. Manual for the laboratory identification of bacterial pathogens of public health importance in the developing world [Internet]. Geneva: World Health Organization; 2003. Available from: https://pdf.usaid.gov/pdf_docs/PNACW461.pdf. Accessed 15 Oct 2018.

37. Chisholm SA, Dave J, Ison CA. High-level azithromycin resistance occurs in Neisseria gonorrhoeae as a result of a single point mutation in the $23 \mathrm{~S}$
rRNA genes. Antimicrob Agents Chemother. 2010;54(9):3812-6. https://doi. org/10.1128/AAC.00309-10.

38. Lindberg R, Fredlund $H$, Nicholas R, Unemo M. Neisseria gonorrhoeae isolates with reduced susceptibility to cefixime and ceftriaxone: association with genetic polymorphisms in penA, mtrR, porB1b, and ponA. Antimicrob Agents Chemother. 2007;51(6):2117-22. https://doi.org/10.1128/AAC.01604-06.

39. Ng LK, Martin I, Liu G, Bryden L. Mutation in 23S rRNA associated with macrolide resistance in Neisseria gonorrhoeae. Antimicrob Agents Chemother. 2002;46(9):3020-5. https://doi.org/10.1128/AAC.46.9.3020-3025.2002.

40. Altman DG, Bland JM. Statistics notes: diagnostic tests 1: sensitivity and specificity. BMJ. 1994;308:1552. https://doi.org/10.1136/bmj.308.6943.1552.

41. Unemo M, Del Rio C, Shafer WM. Antimicrobial resistance expressed by Neisseria gonorrhoeae: a major global public health problem in the 21st Century. Emerg Infect 10. 2016;213-37. https://doi.org/10.1128/microbiolspec.El10-0009-2015.

42. Tapsall JW, Ndowa F, Lewis DA, Unemo M. Meeting the public health challenge of multidrug- and extensively drug-resistant Neisseria gonorrhoeae. Expert Rev Anti Infect Ther. 2009;7(7):821-34. https://doi.org/10.1586/eri.09.63.

43. Maduna LD, Kock MM, Van der Veer BMJW, et al. Antimicrobial resistance of Neisseria gonorrhoeae isolates from high-risk men in Johannesburg, South Africa. Antimicrob Agents Chemother. 2020;(August):1-34. https://doi.org/10.1128/ AAC.00906-20.

44. Rambaran S, Naidoo K, Dookie N, Moodley P, Sturm AW. Resistance profile of Neisseria gonorrhoeae in KwaZulu-Natal, South Africa questioning the effect of the currently advocated dual therapy. Sex Transm Dis. 2019;46(4):266-70. https:// doi.org/10.1097/OLQ.0000000000000961.

45. Kularatne R, Maseko V, Gumede L, Radebe F, Kufa-Chakezha T. Neisseria gonorrhoeae antimicrobial resistance surveillance in Gauteng Province, South Africa. Commun Dis Survelliance Bull. 2016;14(3):56-64.

46. Galarza PG, Abad R, Canigia LF, et al. New mutation in 23S rRNA gene associated with high level of azithromycin resistance in Neisseria gonorrhoeae. Antimicrob Agents Chemother. 2010;54(4):1652-3. https://doi.org/10.1128/AAC.01506-09.

47. Katz AR, Komeya AY, Soge 00, et al. Neisseria gonorrhoeae with high-level resistance to azithromycin: case report of the first isolate identified in the United States. Clin Infect Dis. 2012;54(6):841-3. https://doi.org/10.1093/cid/cir929.

48. Lee $\mathrm{SG}$, Lee $\mathrm{H}$, Jeong $\mathrm{SH}$, et al. Various penA mutations together with $m t r R$, porB and ponA mutations in Neisseria gonorrhoeae isolates with reduced susceptibility to cefixime or ceftriaxone. J Antimicrob Chemother. 2010;65(4):669-75. https:// doi.org/10.1093/jac/dkp505.

49. Ropp PA, Hu M, Olesky M, Nicholas RA. Mutations in ponA, the gene encoding penicillin-binding protein 1 , and a novel locus, penC, are required for high-level chromosomally mediated penicillin resistance in Neisseria gonorrhoeae. Antimicrob Agents Chemother. 2002;46(3):769-77. https://doi.org/10.1128/ AAC.46.3.769-777.2002.

50. Lindbäck E, Islam S, Unemo M, Lang C, Wretlind B. Transformation of ciprofloxacin-resistant Neisseria gonorrhoeae gyrA, parE and porB1b genes. Int J Antimicrob Agents. 2006;28(3):206-11. https://doi.org/10.1016/j. ijantimicag.2006.04.003.

51. Osaka K, Takakura T, Narukawa K, et al. Analysis of amino acid sequences of penicillin-binding protein 2 in clinical isolates of Neisseria gonorrhoeae with reduced susceptibility to cefixime and ceftriaxone. J Infect Chemother. 2008;14(3):195-203. https://doi.org/10.1007/s10156-008-0610-7.

52. Kehrenberg C, Schwarz S. Mutations in 16S rRNA and ribosomal protein S5 associated with high-level spectinomycin resistance in Pasteurella multocida. Antimicrob Agents Chemother. 2007;51(6):2244-6. https://doi.org/10.1128/ AAC.00229-07.

53. Moodley P, Hoppenbrouwers J, Bohlken L, Sturm AW. Emergence of TetM-mediated tetracycline resistance in rural South Africa. J Antimicrob Chemother. 2001;48(1):142-3. https://doi.org/10.1093/jac/48.1.142.

54. Chalkley LJ, Janse van Rensburg MN, Matthee PC, Ison CA, Botha PL. Plasmid analysis of Neisseria gonorrhoeae isolates and dissemination of tetM genes in southern Africa 1993-1995. J Antimicrob Chemother. 1997;40(6):817-22. https:// doi.org/10.1093/jac/40.6.817.

55. Van Dyck E, Rossau R, Duhamel M, et al. Antimicrobial susceptibility of Neisseria gonorrhoeae in Zaire: high level plasmid-mediated tetracycline resistance in central Africa. Genitourin Med. 1992;68(2):111-6. https://doi.org/10.1136/ sti.68.2.111. 


\section{Supplementary data}

ANTIMICROBIAL SUSCEPTIBILITY PATTERNS

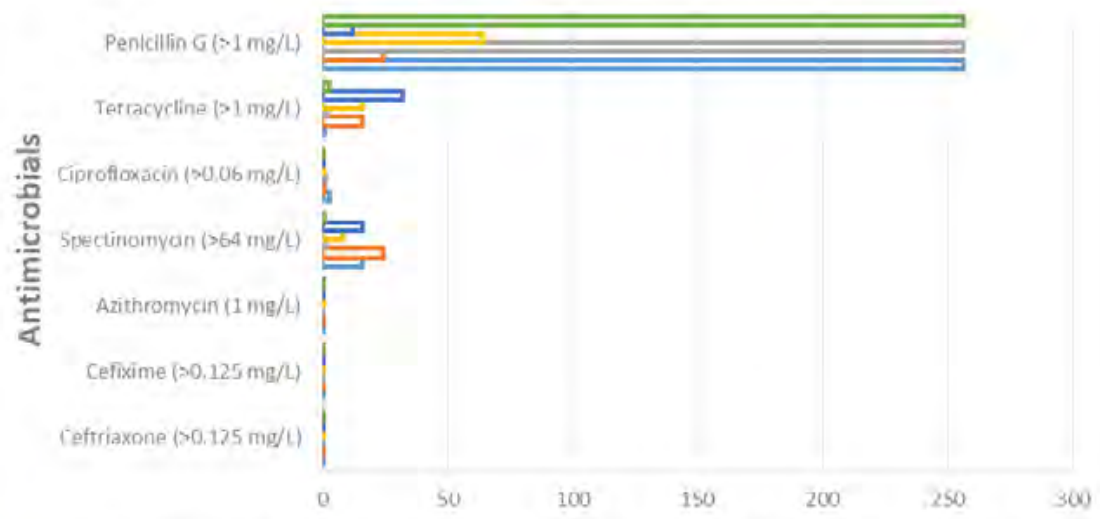

Cettriaxone Celixime Azithromycin Spectinomyan aprofloxacin Tetracycline Penicillur $G(>)$

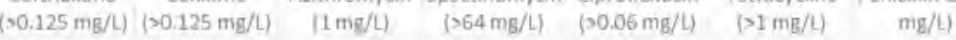

\begin{tabular}{|c|c|c|c|c|c|c|c|}
\hline 口(1) 247 & 0.002 & 0,002 & 0.016 & 0.75 & 0.16 & 3 & 256 \\
\hline $\mathbf{a} G 206$ & 0.006 & 0.016 & 0.094 & 16. & vous & 32 & 12 \\
\hline QG180 & 0.004 & 0.002 & 0.047 & $B$ & 0.5 & 16 & 64 \\
\hline DG176 & 0.002 & 0,0012 & 0,125 & 1.5 & 1.5 & 1.9 & 256 \\
\hline Q $\mathbf{6} 136$ & 0.012 & 0.002 & 0.0594 & 24 & I & 16 & 24 \\
\hline Q 551 & 0.002 & 0.002 & 0.016 & 16. & 3 & 1 & 256 \\
\hline
\end{tabular}

Minimum Inhibitory concentrations

Figure S1: Etest ${ }^{\mathrm{TM}}$ data of emerging antimicrobial susceptibility/resistance patterns in N. gonorrhoeae Patterns of resistance and susceptibility were determined by the 2019 EUCAST breakpoints. 